\title{
GMR
}

\section{Hypoxia enhances periodontal ligament stem cell proliferation via the MAPK signaling pathway}

\author{
Y. He ${ }^{1,2}$, C.X. Jian ${ }^{2}$, H.Y. Zhang ${ }^{1,3}$, Y. Zhou ${ }^{1}$, X. Wu' ${ }^{1}$, G. Zhang ${ }^{1}$ and Y.H. Tan ${ }^{1}$ \\ ${ }^{1}$ Department of Oral and Maxillofacial Surgery, Second Affiliated Hospital, \\ Third Military Medical University, Shapingba District, Chongqing, China \\ ${ }^{2}$ Department of Stomatology, PLA General Hospital of Chengdu Military Region, \\ Chengdu, Sichuan Province, China \\ ${ }^{3}$ Department of Stomatology, 457th Hospital of PLA, Wuhan, Hubei Province, \\ China \\ Corresponding author: Y.H. Tan \\ E-mail: yinghuitanqwe@sina.com \\ Genet. Mol. Res. 15 (4): gmr15048965 \\ Received July 13, 2016 \\ Accepted September 5, 2016 \\ Published November 21, 2016 \\ DOI http://dx.doi.org/10.4238/gmr15048965
}

Copyright (C) 2016 The Authors. This is an open-access article distributed under the terms of the Creative Commons Attribution ShareAlike (CC BY-SA) 4.0 License.

\begin{abstract}
There is high incidence of periodontal disease in highaltitude environments; hypoxia may influence the proliferation and clone-forming ability of periodontal ligament stem cells (PDLSCs). The MAPK signaling pathway is closely correlated with cell proliferation, differentiation, and apoptosis. Thus, we isolated and cultured PDLSCs under hypoxic conditions to clarify the impact of hypoxia on PDLSC proliferation and the underlying mechanism. PDLSCs were separated and purified by the limiting dilution method and identified by flow cytometry. PDLSCs were cultured under hypoxic or normoxic conditions to observe their cloning efficiency. PDLSC proliferation at different oxygen concentrations was evaluated by MTT
\end{abstract}

Genetics and Molecular Research 15 (4): gmr15048965 
assay. Expression of p38/MAPK and MAPK/ERK signaling pathway members was detected by western blotting. Inhibitors for p38/MAPK or ERK were applied to PDLSCs to observe their impacts on clone formation and proliferation. Isolated PDLSCs exhibited typical stem cell morphological characteristics, strong abilities of globular clone formation and proliferation, and upregulated expression of mesenchymal stem cell markers. Stem cell marker expression was not statistically different between PDLSCs cultured under hypoxia and normoxia (P $>0.05)$. The clone number in the hypoxia group was significantly higher than that in the control $(\mathrm{P}<0.05)$. PDLSC proliferation under hypoxia was higher than that of the control $(\mathrm{P}<0.001)$. p38 and ERK1/2 phosphorylation in hypoxic PDLSCs was markedly enhanced compared to that in the control $(\mathrm{P}<0.05)$. Either P38/MAPK inhibitor or ERK inhibitor treatment reduced clone formation and proliferation. Therefore, hypoxia enhanced PDLSC clone formation and proliferation by activating the p38/MAPK and ERK/MAPK signaling pathways.

Key words: Hypoxia; Periodontal ligament stem cells; Cell proliferation; Clone formation

\section{INTRODUCTION}

Periodontitis is one of the most common periodontal diseases. As the main cause of adult tooth loss, periodontitis is characterized as the lack of periodontal support tissue (Hackett and Roach, 2001; Dumitrescu, 2016). Periodontitis has a relatively high incidence; $46 \%$ of Americans exhibit chronic periodontitis (Eke et al., 2015), and the incidence is even higher in developing countries (Corbet, 2006). China exhibits a high incidence of periodontal disease; $80-97 \%$ of adults are affected (Wu et al., 2015). Periodontal health has therefore become a global health problem.

In recent years, tissue engineering repair technology based on the theory of pluripotent cells in periodontal tissue became a hot spot in treating periodontal ligament disease. As an important component of periodontal tissue, periodontal ligaments (PDLs) play a critical role in maintaining the integrity of periodontal tissue (Somerman et al., 1990). PDLs maintain self-renewal and repair capabilities through the function of PDL cells (Trubiani et al., 2016). Numerous evidence demonstrated that stem cells in the PDL are the reason for periodontal tissue regeneration. In 2004, Seo et al. (2004) identified periodontal ligament stem cells (PDLSCs) from periodontal tissue and proposed this concept for the first time. PDLSCs promote the development of tissue engineering because of their characteristic clone-forming ability, proliferation, and pluripotent stem cell differentiation potential (Mattioli-Belmonte et al., 2015; Vandana et al., 2015).

However, the function of PDLSCs is regulated by various factors, including external stimuli and immune status. Many epidemiological studies reported that the incidence of periodontitis in residents living in areas with altitudes over 4000 meters was significantly higher than that in residents living at sea level (Jian et al., 2014). Animal experiments also revealed that hypoxia may induce severe periodontitis (Xiao et al., 2012; Terrizzi et al., 2013). The abovementioned evidence showed that hypoxic microenvironments may contribute to

Genetics and Molecular Research 15 (4): gmr15048965 
periodontal cells' inability to regenerate. Furthermore, a previous study also demonstrated that exposure of PDLSCs to hypoxia affected their osteogenic potential, mineralization, and paracrine release (Wu et al., 2013). However, whether hypoxia exerts an effect on PDLSC proliferation remains poorly understood. Thus, we speculated that hypoxia may obstruct the self-renewing ability of PDLSCs. In this study, we clarified the impact of hypoxia on PDLSC proliferation and clone formation by isolating PDLSCs and cultivating them under hypoxia.

The mitogen-activated protein kinase (MAPK) signaling pathway is one of the most important biological signaling pathways. Its activation regulates a variety of cellular behaviors such as cell proliferation, differentiation, and apoptosis. The MAPK signaling pathway, including members p38 and ERK, plays a key role in the ability of bone marrow mesenchymal stem cells to differentiate into osteogenic cells (Jaiswal et al., 2000; Liu et al., 2009), and is related to cell self-renewal (Wang et al., 2016; Xu et al., 2016). Hypoxia can activate the p38/ MAPK and MAPK/ERK signaling pathways (Qiu et al., 2016). Therefore, this study explored the impact of hypoxia on PDLSC self-renewal and related mechanisms, by regulating the expression and activity of p38/MAPK and MAPK/ERK signaling pathway-related proteins.

\section{MATERIAL AND METHODS}

\section{Main instruments and reagents}

DMEM medium was obtained from Gibco. Fetal bovine serum was obtained from Every Green Co., Ltd. (China). Penicillin-streptomycin was obtained from Hyclone. PBS was obtained from ZSbio. Type II collagenase and MTT were obtained from Sigma. PE-labeled STRO-1, CD146, CD44, and CD45 antibodies were obtained from Bioscience. RIPA lysis buffer was obtained from Beyotime. BCA protein quantification kit was from Shanghai Shengneng Bocai Co., Ltd. HRP-labeled mouse anti-human GAPDH monoclonal antibody was obtained from KangChen. Protein marker was obtained from Tiangen Biotech Co., Ltd. PVDF membranes were obtained from Millipore. The FC 500 MPL flow cytometry system was from Beckman. The automatic model 680 microplate reader was from Bio-Rad. X-ray film was from Fuji. The dental X-ray machine 2200 was from Eastman Kodak. Vertical electrophoresis apparatus E5889 was from Sigma. The 3111 water jacketed $\mathrm{CO}_{2}$ incubator was from Thermo.

\section{Human PDLSC isolation and cultivation}

The third molar from 15 healthy donors (Han Chinese nationality) with a median age of 39 years (range: 18-56 years) received dental orthodontic treatment in the Second Affiliated Hospital, Third Military Medical University. The tissue was washed with PBS containing penicillin-streptomycin and periodontal tissue was isolated from the root of tooth. The tissue was cut with sterile scissors to a size of 1-3 $\mathrm{mm}$ and placed to a centrifuge tube. After centrifugation at $1200 \mathrm{rpm}$ for $5 \mathrm{~min}$, the tissue was treated with type II collagenase and oscillation-digested in a $37^{\circ} \mathrm{C}$ constant temperature water bath for $1.5 \mathrm{~h}$. Next, the tissue was filtered through a $70-\mu \mathrm{m}$ mesh and centrifuged at $1000 \mathrm{rpm}$ for $5 \mathrm{~min}$ to prepare a single cell suspension. The cells were washed in DMEM supplemented with $10 \%$ FBS and penicillinstreptomycin three times and seeded in cell culture dishes at $1 \times 10^{4}$ cells $/ \mathrm{mL}$. Cells were cultured at $37^{\circ} \mathrm{C}$ and $5 \% \mathrm{CO}_{2}$ and medium was changed every 3-5 days. All donors gargled

Genetics and Molecular Research 15 (4): gmr15048965 
with chlorhexidine before tooth extraction. Preoperative X-rays showed no dental caries, periodontal disease, bone absorption, or root lesions. The experiment was approved by the Ethics Committee of Second Affiliated Hospital, Third Military Medical University, and informed consent was obtained from all subjects.

\section{Flow cytometry}

PDLSCs were seeded on six-well plates at $1 \times 10^{6} \mathrm{cells} / \mathrm{well}$ and then were assigned to hypoxia or normoxia groups. Cells in the hypoxia group were incubated in $37^{\circ} \mathrm{C}, 5 \% \mathrm{CO}_{2}$, and $5 \% \mathrm{O}_{2}$, whereas the cells in the normoxia group were maintained in $37^{\circ} \mathrm{C}, 5 \% \mathrm{CO}_{2}$, and $20 \%$ $\mathrm{O}_{2}$. The cells were digested with $0.25 \%$ trypsin when the confluency reached $80 \%$ and were then resuspended at $1 \times 10^{6}$ cells $/ \mathrm{mL}$. PDLSCs in $100 \mu \mathrm{L}$ PBS were stained with $5 \mu \mathrm{L}$ PElabeled antibodies against STRO-1, CD44, CD45, and CD146, and then incubated at $4^{\circ} \mathrm{C}$ in the dark for $30 \mathrm{~min}$. After centrifugation at $2000 \mathrm{rpm}$ for $5 \mathrm{~min}$, cells were resuspended in 500 $\mu \mathrm{L}$ PBS and analyzed by flow cytometry. All experiments were repeated at least three times.

\section{MTT assay}

Cell proliferation was detected by an MTT kit (Sigma, St. Louis, MO, USA) according to the manufacturer protocol. PDLSCs were seeded on 96 -well plates at $5 \times 10^{3}$ cells $/$ well and incubated under hypoxia or normoxia. After intervention, $20 \mu \mathrm{L}$ MTT at $5 \mathrm{mg} / \mathrm{mL}$ was added to each well and the plate was incubated at $37^{\circ} \mathrm{C}$ for $3 \mathrm{~h}$. Finally, the plates were treated with $150 \mu \mathrm{L}$ DMSO to resolve the crystals, and optical density at $570 \mathrm{~nm}$ was read. The experiments were repeated at least three times.

\section{Clone formation assay}

PDLSCs were seeded on six-well plates at $1 \times 10^{6}$ cells/well and subjected to either hypoxia or normoxia. The cells were digested with $0.25 \%$ trypsin and washed with PBS three times. Next, cells were seeded on 96-well plates at different concentrations $\left(1 \times 10^{4}, 1 \times 10^{3}\right.$, and $1 \times 10^{2}$ cells/ well). After 14 days of culture, the cells were fixed in $10 \%$ methanol and stained with $0.5 \%$ crystal violet. Then, cell clones was observed under the microscope. Clones containing more than 50 cells were considered positive. Cloning efficiency $=$ clone number $/$ seeded cell number $\times 100 \%$.

\section{Western blotting}

After hypoxic intervention, PDLSCs were incubated with RIPA buffer on ice for 30 $\mathrm{min}$ and centrifuged at $12,000 \mathrm{rpm}$ for $25 \mathrm{~min}$. The protein contents of the collected supernatant were quantified by BCA kit according to the manufacturer protocol. A total of $20 \mu \mathrm{g}$ protein was mixed with $105 \mu \mathrm{L}$ water and $125 \mu \mathrm{L}$ Laemmli loading buffer containing dithiothreitol at $54 \mathrm{mg} / \mathrm{mL}$, and boiled at $100^{\circ} \mathrm{C}$ for $10 \mathrm{~min}$. Proteins were separated by SDS-PAGE at 180 $\mathrm{V}$ for $1 \mathrm{~h}$, and then transferred to PVDF membranes at $100 \mathrm{~mA}$ for $80 \mathrm{~min}$. After blocking with 5\% skim milk, the membrane was incubated with the appropriate primary antibody at $4^{\circ} \mathrm{C}$ overnight. Next, the membrane was washed with TBST five times and incubated in the appropriate HRP-labeled secondary antibody at $37^{\circ} \mathrm{C}$ for $1 \mathrm{~h}$. Finally, the membrane was incubated with ECL reagent at $22^{\circ} \mathrm{C}$ for 2-3 min and exposed to X-ray film.

Genetics and Molecular Research 15 (4): gmr15048965 


\section{Statistical analysis}

The SPSS19.0 software was utilized for data analysis. Normally distributed data are reported as means \pm standard deviation and groups were compared by the Student $t$-test. A significant difference was considered when $\mathrm{P}<0.05$.

\section{RESULTS}

\section{PDLSC isolation, cultivation, and identification}

After 14 days of cultivation, cell morphology was observed as shown in Figure 1A. The cells exhibited long fusiform or irregular shapes, small volume, and spiral or radial alignment, similar to known characteristics of periodontal ligament cells.

PDLSCs were seeded on 96-well plates and cultured for 21 days to observe clone formation. As shown in Figure 1B, the clone number in PDLSCs was significantly higher than that observed in PDL cells $(\mathrm{P}<0.05)$.

Flow cytometry was performed to test for stem cell surface marker expression on PDLSCs and PDL cells. The expression rates of STRO-1, CD146, CD44, and CD45 on PDLSCs were 93.4, 92.8, 93.6, and 2.4\%, respectively, which was significantly higher than their expressions on the PDL cell surfaces at 1.8, 2.2, 2.8, and 1.6\%, respectively $(\mathrm{P}<0.05)$.

MTT assays were performed to determine cell proliferation, and the proliferative ability of PDLSCs on days 3-7 was markedly higher than that of PDL cells $(\mathrm{P}<0.05)$ (Figure $1 \mathrm{C}$ and $\mathrm{D})$.

A

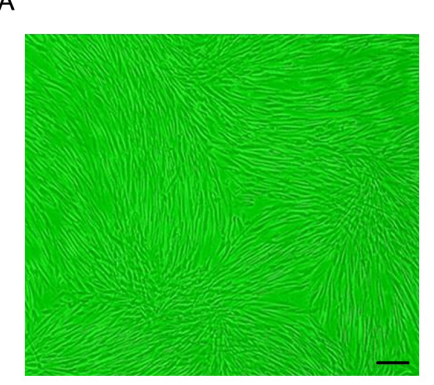

C

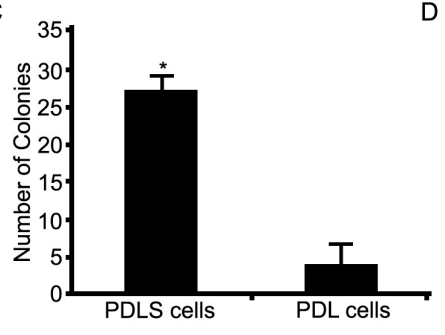

B
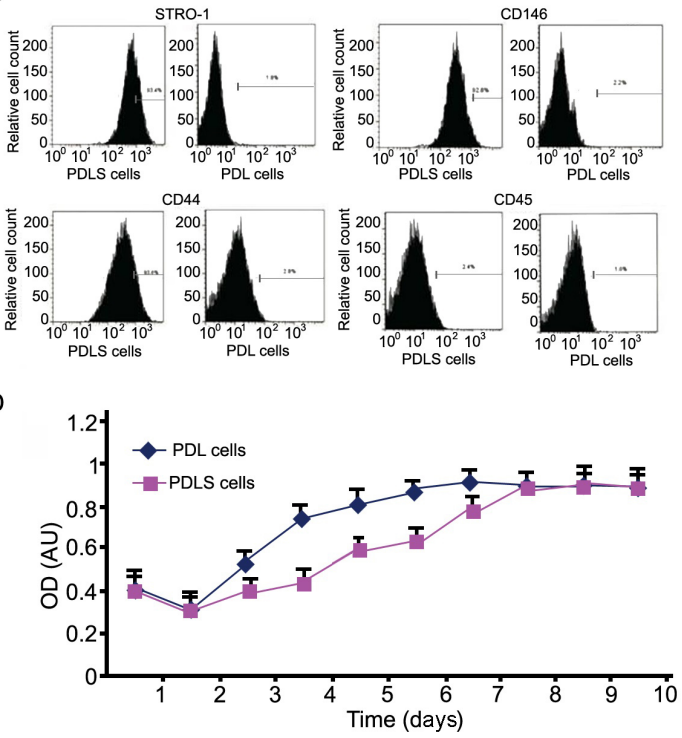

Figure 1. PDLSC isolation, cultivation, and identification. Tissues were extracted and a single cell suspension was prepared, followed by seeding onto cell culture dishes. A. Cells cultured under normal conditions for morphologic analysis of the isolated PDLSCs by microscopy. Bar $=100 \mu \mathrm{m}$. B. Cells collected for analysis of stem cell surface marker expression (STRO-1, CD146, CD44, and CD45) by flow cytometry. C. Clone formation and D. cell proliferation by MTT assay. 


\section{Impact of hypoxia on PDLSC surface marker expression}

To explore the effect of hypoxia in maintaining PDLSC self-renewal ability and pluripotency, PDLSCs were cultured under hypoxia or normoxia for 7 days. Flow cytometry was performed to examine stem cell marker expression on PDLSCs. As shown in Figure 2, STRO-1, CD146, CD44, and CD45 levels showed no statistical difference between the hypoxia and normoxia groups $(\mathrm{P}>0.05)$, indicating that PDLSCs can maintain pluripotency under hypoxic conditions.
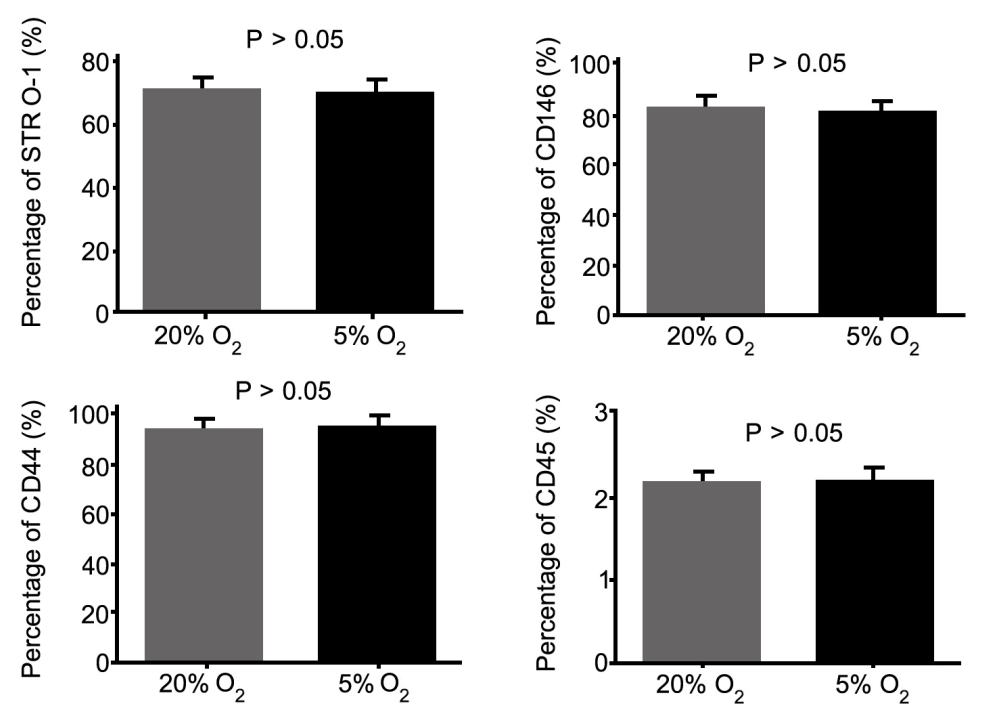

Figure 2. Impact of hypoxia on PDLSC surface marker expression.

\section{Effect of hypoxia on PDLSC clone-forming ability}

PDLSC clone-forming ability was evaluated after hypoxic culture for 14 days. As shown in Figure 3, the clone number of PDLSCs in the hypoxia group was significantly higher than that in the control $(\mathrm{P}<0.05)$.
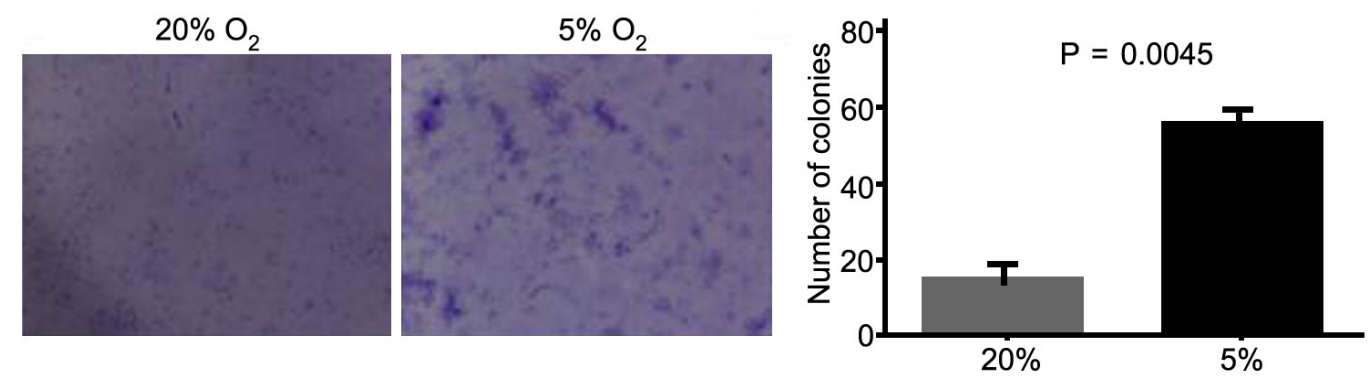

Figure 3. Effect of hypoxia on PDLSC clone formation ability.

Genetics and Molecular Research 15 (4): gmr15048965 


\section{Influence of hypoxia on PDLSC proliferation}

MTT assays were adopted to determine PDLSC proliferation under different oxygen concentrations and time points. As shown in Figure 4, PDLSC proliferation rate in the hypoxic group was significantly different from that in the control. On days 3-6, the rate of PDLSC proliferation under hypoxia was obviously higher than that in the control $(\mathrm{P}<0.001)$.

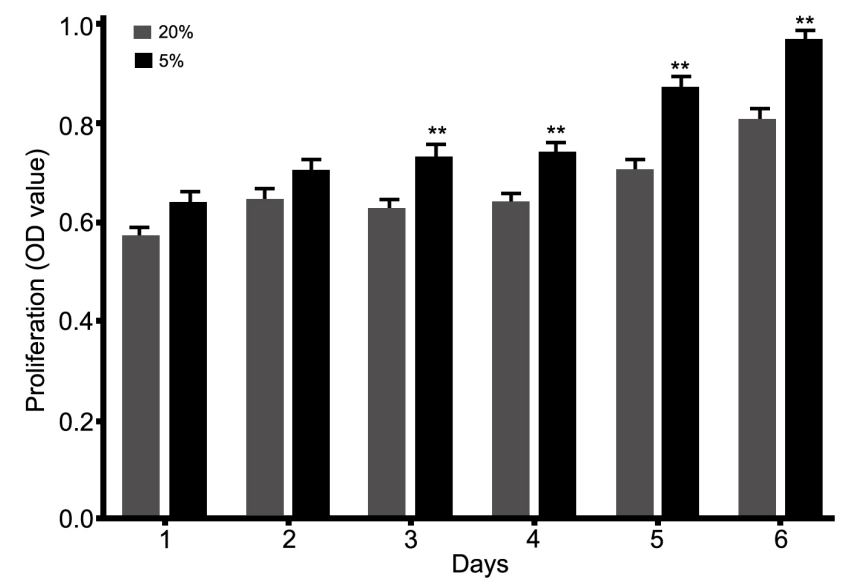

Figure 4. Influence of hypoxia on PDLSC proliferation. ${ }^{* *} \mathrm{P}<0.001$ vs control.

\section{Hypoxia activates p38/MAPK and MAPK/ERK signaling pathways in PDLSCs}

It was reported that the p38/MAPK and MAPK/ERK signaling pathways are related to PDLSC self-renewal (Bernet et al., 2014; Sun et al., 2015; Rodríguez-Carballo et al., 2016). Therefore, western blotting was performed to detect related protein expression in PDLSCs after hypoxic culture for $48 \mathrm{~h}$ (Figure 5). Total p38 and ERK1/2 protein levels were not significantly different in PDLSCs grown under different oxygen concentrations, whereas p38 and ERK1/2 phosphorylation was markedly increased in the hypoxia group compared with that in the control $(\mathrm{P}<0.05)$.
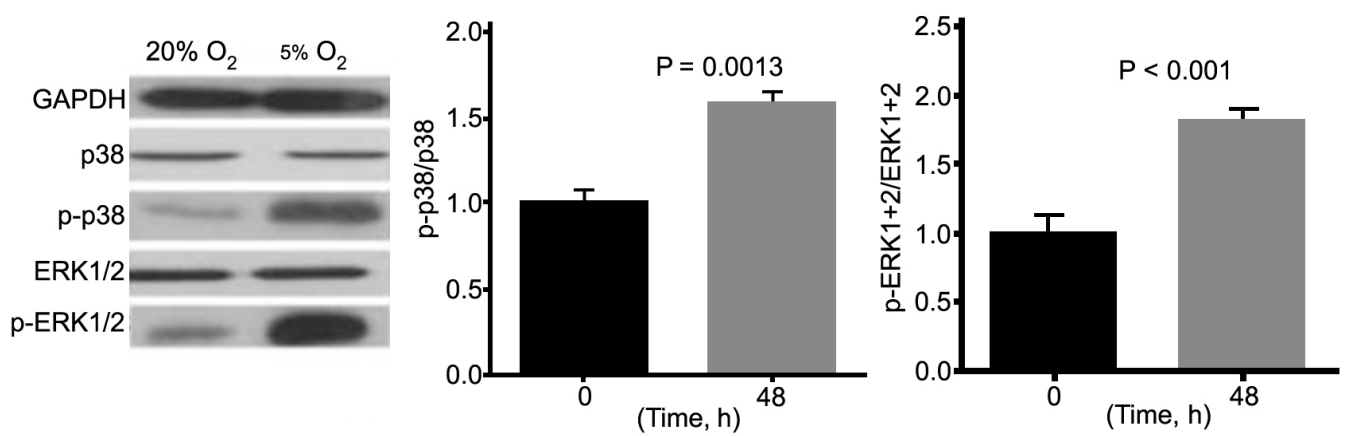

Figure 5. Hypoxia activated p38/MAPK and MAPK/ERK signaling pathways in PDLSCs. 


\section{Enhancement of PDLSC clone formation and proliferation is related to p38/ MAPK and MAPK/ERK signaling pathway activation}

To investigate the impact of the MAPK signaling pathway on PDLSC self-renewal under hypoxic conditions, p38/MAPK or ERK inhibitors were used to pretreat PDLSCs. As shown in Figure 6, PDLSC clone formation and proliferation in the p38/MAPK inhibitor group, ERK inhibitor group, and p38/MAPK + ERK inhibitor group were significantly lower than in the control $(\mathrm{P}<0.05)$.
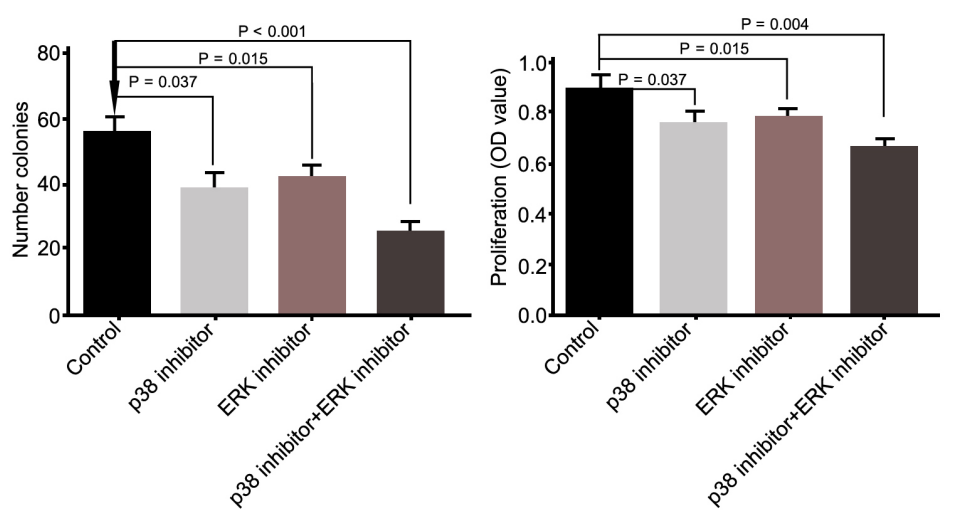

Figure 6. ERK and p38 inhibition suppressed PDLSC clone formation and proliferation under hypoxia.

\section{DISCUSSION}

The current methods for adult stem cell separation include immunomagnetic cell sorting, density gradient centrifugation, and continuous clonal cultivation. For PDLSCs, the main isolation method is limiting dilution. Therefore, in this study, we applied the limiting dilution method to separate and purify PDLSCs from molars of healthy adults. The typical ultrastructure of stem cells could be observed in these cells by optical microscopy. Another important feature of stem cells is their strong ability to form spherical clones. It was reported that PDLSCs formed spherical clones after culture for 10-15 days (Yang et al., 2009). Our study also revealed that the clone number in PDLSCs was significantly higher than that observed for PDL cells, in accordance with a previous report (Gay et al., 2007). This result indicated that these cells have strong self-renewal ability. In addition, PDLSCs show characteristics of mesenchymal stem cells. In addition to STRO-1 and CD146 expression, these cells also express CD105/14/44/106/166/106/166 (Tang et al., 2014; Park et al., 2015). Therefore, flow cytometry was applied to identify stem cell markers on PDLSCs. PDLSCs highly expressed the stem cell markers, including STRO-1, CD146, CD44, and CD45, indicating that PDLSCs were successfully isolated from the periodontal tissue.

Oxygen is an important element that maintains organ function and homeostasis. Hypoxia can promote osteoblast proliferation in the periodontal microenvironment ( $\mathrm{Li}$ et al., 2015), as well as periodontal ligament fibroblast proliferation (Zhang et al., 2013), revealing that hypoxic environments may affect PDLSC proliferation. Therefore, PDLSCs were cultured under hypoxia and normoxia to examine the influence of hypoxia on PDLSCs. Hypoxia clearly enhanced PDLSC clone formation and proliferation, revealing that PDLSCs can maintain their 
self-renewal ability in vitro under hypoxic conditions. Amemiya et al. (2008) reported that hypoxia can promote the proliferation of periodontal ligament cells. Consistent with this, a previous study (Zhang et al., 2014) also showed that upon exposing human PDLSCs to hypoxia for 7 days, the proliferation rate was increased and a higher osteogenic differentiation potential than that of control cells was observed. Twelve weeks after transplantation, hypoxia-treated PDLSCs differentiated into osteoblast-like cells that formed bone-like structures (Zhang et al., 2014).

In addition, we also explored the mechanism of hypoxia that promotes PDLSC clone formation and proliferation. p38 and ERK1/2 phosphorylation was significantly enhanced in PDLSCs after hypoxic intervention, whereas p38/MAPK or ERK/MAPK inhibition effectively suppressed PDLSC proliferation and clone formation. This result indicated that PDLSC selfrenewal under hypoxia is regulated by the p38/MAPK and ERK/MAPK signaling pathways. Matsuda et al. (1998) reported that hypoxia can activate ERK1/2 to regulate the proliferation of periodontal ligament cells.

Therefore, we successfully separated and cultured PDLSCs and investigated the impact of hypoxia on their proliferation and clone-forming ability. Hypoxia enhanced clone formation and proliferation by activating the $\mathrm{p} 38$ /MAPK and ERK/MAPK signaling pathways, indicating that PDLSC self-renewal is maintained under hypoxia. However, we were unable to provide an explanation for the high incidence of periodontal disease at high elevations; thus, further investigation is needed to clarify the effect of hypoxia on PDLSCs.

\section{CONCLUSION}

Hypoxia can enhance PDLSC clone formation and proliferation, which may be related to the activation of the p38/MAPK and ERK/MAPK signaling pathways.

\section{Conflicts of interest}

The authors declare no conflict of interest.

\section{ACKNOWLEDGMENTS}

We thank the anonymous reviewers for reviewing this manuscript.

\section{REFERENCES}

Amemiya H, Matsuzaka K, Kokubu E, Ohta S, et al. (2008). Cellular responses of rat periodontal ligament cells under hypoxia and re-oxygenation conditions in vitro. J. Periodontal Res. 43: 322-327. http://dx.doi.org/10.1111/j.1600$\underline{0765.2007 .01032 . x}$

Bernet JD, Doles JD, Hall JK, Kelly Tanaka K, et al. (2014). p38 MAPK signaling underlies a cell-autonomous loss of stem cell self-renewal in skeletal muscle of aged mice. Nat. Med. 20: 265-271. http://dx.doi.org/10.1038/nm.3465

Corbet EF (2006). Periodontal diseases in Asians. J. Int. Acad. Periodontol. 8: 136-144.

Dumitrescu AL (2016). Editorial: Periodontal Disease - A Public Health Problem. Front. Public Health 3: 278. http:// dx.doi.org/10.3389/fpubh.2015.00278

Eke PI, Dye BA, Wei L, Slade GD, et al. (2015). Update on prevalence of periodontitis in adults in the United States: NHANES 2009 to 2012. J. Periodontol. 86: 611-622. http://dx.doi.org/10.1902/jop.2015.140520

Gay IC, Chen S and MacDougall M (2007). Isolation and characterization of multipotent human periodontal ligament stem cells. Orthod. Craniofac. Res. 10: 149-160. http://dx.doi.org/10.1111/j.1601-6343.2007.00399.x

Hackett PH and Roach RC (2001). High-altitude illness. N. Engl. J. Med. 345: 107-114. http://dx.doi.org/10.1056/ NEJM200107123450206

Genetics and Molecular Research 15 (4): gmr15048965 
Jaiswal RK, Jaiswal N, Bruder SP, Mbalaviele G, et al. (2000). Adult human mesenchymal stem cell differentiation to the osteogenic or adipogenic lineage is regulated by mitogen-activated protein kinase. J. Biol. Chem. 275: 9645-9652. http://dx.doi.org/10.1074/jbc.275.13.9645

Jian C, Li C, Ren Y, He Y, et al. (2014). Hypoxia augments lipopolysaccharide-induced cytokine expression in periodontal ligament cells. Inflammation 37: 1413-1423.http://dx.doi.org/10.1007/s10753-014-9865-6

Li Q, Yu B and Yang P (2015). Hypoxia-induced HMGB1 in would tissues promotes the osteoblast cell proliferation via activating ERK/JNK signaling. Int. J. Clin. Exp. Med. 8: 15087-15097.

Liu Q, Cen L, Zhou H, Yin S, et al. (2009). The role of the extracellular signal-related kinase signaling pathway in osteogenic differentiation of human adipose-derived stem cells and in adipogenic transition initiated by dexamethasone. Tissue Eng. Part A 15: 3487-3497. http://dx.doi.org/10.1089/ten.tea.2009.0175

Matsuda N, Morita N, Matsuda K and Watanabe M (1998). Proliferation and differentiation of human osteoblastic cells associated with differential activation of MAP kinases in response to epidermal growth factor, hypoxia, and mechanical stress in vitro. Biochem. Biophys. Res. Commun. 249: 350-354.http://dx.doi.org/10.1006/bbrc.1998.9151

Mattioli-Belmonte M, Teti G, Salvatore V, Focaroli S, et al. (2015). Stem cell origin differently affects bone tissue engineering strategies. Front. Physiol. 6: 266. http://dx.doi.org/10.3389/fphys.2015.00266

Park SY, Kim KH, Gwak EH, Rhee SH, et al. (2015). Ex vivo bone morphogenetic protein 2 gene delivery using periodontal ligament stem cells for enhanced re-osseointegration in the regenerative treatment of peri-implantitis. $J$. Biomed. Mater. Res. A 103: 38-47. http://dx.doi.org/10.1002/jbm.a.35145

Qiu X, Zheng M, Song D, Huang L, et al. (2016). Notoginsenoside Rb1 inhibits activation of ERK and p38 MAPK pathways induced by hypoxia and hypercapnia. Exp. Ther. Med. 11: 2455-2461.

Rodríguez-Carballo E, Gámez B and Ventura F (2016). p38 MAPK Signaling in Osteoblast Differentiation. Front. Cell Dev. Biol. 4: 40.http://dx.doi.org/10.3389/fcell.2016.00040

Seo BM, Miura M, Gronthos S, Bartold PM, et al. (2004). Investigation of multipotent postnatal stem cells from human periodontal ligament. Lancet 364: 149-155. http://dx.doi.org/10.1016/S0140-6736(04)16627-0

Somerman MJ, Young MF, Foster RA, Moehring JM, et al. (1990). Characteristics of human periodontal ligament cells in vitro. Arch. Oral Biol. 35: 241-247. http://dx.doi.org/10.1016/0003-9969(90)90062-F

Sun Y, Liu WZ, Liu T, Feng X, et al. (2015). Signaling pathway of MAPK/ERK in cell proliferation, differentiation, migration, senescence and apoptosis. J. Recept. Signal Transduct. Res. 35: 600-604. http://dx.doi.org/10.3109/1079 $\underline{9893.2015 .1030412}$

Tang R, Wei F, Wei L, Wang S, et al. (2014). Osteogenic differentiated periodontal ligament stem cells maintain their immunomodulatory capacity. J. Tissue Eng. Regen. Med. 8: 226-232. http://dx.doi.org/10.1002/term.1516

Terrizzi AR, Fernandez-Solari J, Lee CM, Bozzini C, et al. (2013). Alveolar bone loss associated to periodontal disease in lead intoxicated rats under environmental hypoxia. Arch. Oral Biol. 58: 1407-1414. http://dx.doi.org/10.1016/j. archoralbio.2013.06.010

Trubiani O, Giacoppo S, Ballerini P, Diomede F, et al. (2016). Alternative source of stem cells derived from human periodontal ligament: a new treatment for experimental autoimmune encephalomyelitis. Stem Cell Res. Ther. 7: 1. http://dx.doi.org/10.1186/s13287-015-0253-4

Vandana KL, Desai R and Dalvi PJ (2015). Autologous Stem Cell Application in Periodontal Regeneration Technique (SAI-PRT) Using PDLSCs Directly From an Extracted Tooth - An Insight. Int. J. Stem Cells 8: 235-237.http:// dx.doi.org/10.15283/ijsc.2015.8.2.235

Wang Z, Wang W, Xu S, Wang S, et al. (2016). The role of MAPK signaling pathway in the Her-2-positive meningiomas. Oncol. Rep. 36: 685-695.

Wu RX, Bi CS, Yu Y, Zhang LL, et al. (2015). Age-related decline in the matrix contents and functional properties of human periodontal ligament stem cell sheets. Acta Biomater. 22: 70-82. http://dx.doi.org/10.1016/j.actbio.2015.04.024

Wu Y, Yang Y, Yang P, Gu Y, et al. (2013). The osteogenic differentiation of PDLSCs is mediated through MEK/ ERK and p38 MAPK signalling under hypoxia. Arch. Oral Biol. 58: 1357-1368. http://dx.doi.org/10.1016/j. archoralbio.2013.03.011

Xiao X, Li Y, Zhang G, Gao Y, et al. (2012). Detection of bacterial diversity in rat's periodontitis model under imitational altitude hypoxia environment. Arch. Oral Biol. 57: 23-29. http://dx.doi.org/10.1016/j.archoralbio.2011.07.005

$\mathrm{Xu}$ CL, Zheng B, Pei JH, Shen SJ, et al. (2016). Embelin induces apoptosis of human gastric carcinoma through inhibition of $\mathrm{p} 38$ MAPK and NF-кB signaling pathways. Mol. Med. Rep. 14: 307-312.

Yang ZH, Zhang XJ, Dang NN, Ma ZF, et al. (2009). Apical tooth germ cell-conditioned medium enhances the differentiation of periodontal ligament stem cells into cementum/periodontal ligament-like tissues. J. Periodontal Res. 44: 199-210. http://dx.doi.org/10.1111/j.1600-0765.2008.01106.x

Zhang HY, Liu R, Xing YJ, Xu P, et al. (2013). Effects of hypoxia on the proliferation, mineralization and ultrastructure of human periodontal ligament fibroblasts in vitro. Exp. Ther. Med. 6: 1553-1559.

Zhang QB, Zhang ZQ, Fang SL, Liu YR, et al. (2014). Effects of hypoxia on proliferation and osteogenic differentiation of periodontal ligament stem cells: an in vitro and in vivo study. Genet. Mol. Res. 13: 10204-10214. http://dx.doi. org/10.4238/2014.December.4.15

Genetics and Molecular Research 15 (4): gmr15048965 